\title{
Interactive comment on "Leads and ridges in Arctic sea ice from RGPS data and a new tracking algorithm" by Nils Hutter et al.
}

\section{Nils Hutter et al. \\ nils.hutter@awi.de}

Received and published: 30 January 2019

The formatted answers to anonymous referee \#2 can be found in the supplement pdf.

Please also note the supplement to this comment:

https://www.the-cryosphere-discuss.net/tc-2018-207/tc-2018-207-AC2-

supplement.pdf

Interactive comment on The Cryosphere Discuss., https://doi.org/10.5194/tc-2018-207, 2018. 